\title{
Trends and projections of storm formation in coupled climate models
}

\author{
$\begin{array}{lll}\text { C. S. Frederiksen } & & \text { J. S. Frederiksen } \\ & \text { J. M. Sisson }\end{array}$ \\ S. L. Osbrough ${ }^{4}$
}

(Received 13 March 2015; revised 10 January 2016)

\begin{abstract}
Changes in the characteristics of southern hemisphere storms, in all seasons, during the second half of the twentieth century, were related to changes in the annual cycle of southern hemisphere baroclinic instability. In particular, significant negative trends in baroclinic instability were found in a mid-latitude zonal band in all months; a similar band of significant positive trends occurs further poleward. Corresponding to this decrease/increase in baroclinic instability there was a decrease/ increase in storm formation at these latitudes, and in some cases a preference for storm formation further poleward than normal. These changes in the weather systems are consistent with the observed negative trends in southern Australian rainfall. Future projections of trends
\end{abstract}

http://journal . austms.org.au/ojs/index.php/ANZIAMJ/article/view/9406 gives this article, (c) Austral. Mathematical Soc. 2016. Published January 31, 2016, as part of the Proceedings of the 17th Biennial Computational Techniques and Applications Conference. ISSN 1446-8735. (Print two pages per sheet of paper.) Copies of this article must not be made otherwise available on the internet; instead link directly to this URL for this article. 
in baroclinicity, under the RCP8.5 scenario, show a similar pattern of negative and positive trends during the second half of the twenty first century. The impact of these trends is continuing decreased and negative trends in southern Australian rainfall.

\section{Contents}

1 Introduction

C280

2 Datasets

C281

3 Phillips criterion of baroclinic instability

C281

4 Changes in storm track modes

C285

5 CMIP5 models and future projections

C289

6 Conclusion

C292

References

C293

\section{Introduction}

Over the last sixty years there has been a steady downward trend in autumn to spring rainfall over much of southern Australia, and especially during winter over southwest Western Australia [1, 2]. These trends were associated with large-scale changes in the global atmospheric circulation and influenced southern hemisphere cyclogenesis, with a reduction in the intensity of storm formation and the southward deflection of some storms [3, 4]. These changes in storm formation, and consequently rainfall, were related to long term trends in the baroclinic instability of the southern hemisphere circulation [3], as measured by the Phillips criterion [5], discussed in Section 3. 
In this article, the observed changes and trends in the annual cycle of southern hemisphere baroclinicity is considered. Section 4 identifies the implications for changes in midlatitude $\left(25^{\circ} \mathrm{S}\right.$ to $\left.65^{\circ} \mathrm{S}\right)$ storm formation by calculating the fastest growing storm track modes. These changes are then related to observed changes in southern Australian rainfall. Section 5 examines projections of possible changes in baroclinic instability under the representative concentration pathways 8.5 (RCP8.5) [6] using an ensemble of Coupled Model Intercomparison Project phase five (CMIP5) [7] climate models. The implications for storm formation and southern Australian rainfall is then discussed.

\section{Datasets}

The observed large scale atmospheric circulation fields used in this study are the National Centers for Environmental Prediction (NCEP) and National Center for Atmospheric Research (NCAR) reanalysis data [9]. In addition, we use CMIP5 model datasets. Flato et al. [10] described the CMIP5 models. Specifically, data fields from the CMIP5 historical experiment are used to evaluate the models and to choose a subset of the best models to study future projections of changes to Southern Hemisphere storms [7]. The RCP8.5 [6] scenario is used to study the impact of continuing increasing trends in anthropogenic greenhouse gases on storm development and, consequently, southern Australian rainfall. The RCP8.5 is the pathway with the largest radiative forcing of about $8.5 \mathrm{~W} \mathrm{~m}^{-2}$, or an equivalent $\mathrm{CO}_{2}$ concentration of about $1360 \mathrm{ppm}$, by the year 2100 with no stabilisation [6].

\section{Phillips criterion of baroclinic instability}

The baroclinic instability of the atmospheric circulation is described by the Phillips criterion [5], which is a simple diagnostic that provides a measure of 
incipient storm development [3]:

$$
u^{300}-u^{700}-\frac{b_{k} c_{p} \sigma\left(1-\mu^{2}\right)^{1 / 2}}{a \Omega \mu^{2}} \geqslant 0 .
$$

Here, $\mathfrak{u}^{300}$ and $\mathfrak{u}^{700}$ represent the $300 \mathrm{hPa}$ and $700 \mathrm{hPa}$ zonal velocities, and $\sigma$ is the static stability, calculated here as half the difference between the potential temperature at $300 \mathrm{hPa}$ and $700 \mathrm{hPa}$. Also $c_{\mathrm{p}}=1004 \mathrm{~J} \mathrm{~K}^{-1} \mathrm{~kg}^{-1}$ is the specific heat of air at constant pressure, $\Omega=7.292 \times 10^{-5} \mathrm{rads}^{-1}$ is the earth's angular speed of rotation, $b_{\mathrm{k}}=0.124$ is a dimensionless constant, $a=6.371 \times 10^{6} \mathrm{~m}$ is the radius of the earth, and $\mu$ is the sine of latitude. Near the equator the Phillips criterion (1) is always negative and is therefore mostly relevant for the development of extra-tropical or mid-latitude storms. The more positive the criterion, the more unstable is the atmosphere and the greater the chance of developing storms.

While the entire annual monthly cycle of the Phillips criterion (1) was considered, the focus in this article is on the central month of each season, that is, January, April, July and October. Figure 1 shows the climatology of the Phillips criterion, calculated from the NCEP reanalysis dataset, for these four months over the period 1950-1999. For April, July and October, the largest values in the criterion occur in the region of the subtropical jet near $30^{\circ} \mathrm{S}$, with smaller values in the region of the polar jet $40-50^{\circ} \mathrm{S}$. In contrast, during January the largest values occur in the region of the polar jet. Thus, there is a preference for storm development on the polar jet during the warmer months and the subtropical jet during the cooler months.

Figure 2 shows the linear trends in the Phillips criterion of Figure 1 over the period 1950-1999. Trends significant at the 95\% level are shaded. For each month there are significant negative trends in the lower latitudes, and especially over the southern Indian Ocean upstream of Australia, with values less than $-0.12 \mathrm{~m} \mathrm{~s}^{-1}$ year $^{-1}$. These regions correspond approximately to those regions of largest Phillips criterion seen in the climatology, suggesting a reduction in the development of storms in these regions over time. In the higher latitudes, significant positive trends occur with values as large 
Figure 1: NCEP Phillips criterion climatology $\left(\mathrm{m} \mathrm{s}^{-1}\right)$ during 1950-1999, for January, April, July and October.

\section{Phillips Criterion Climatology}

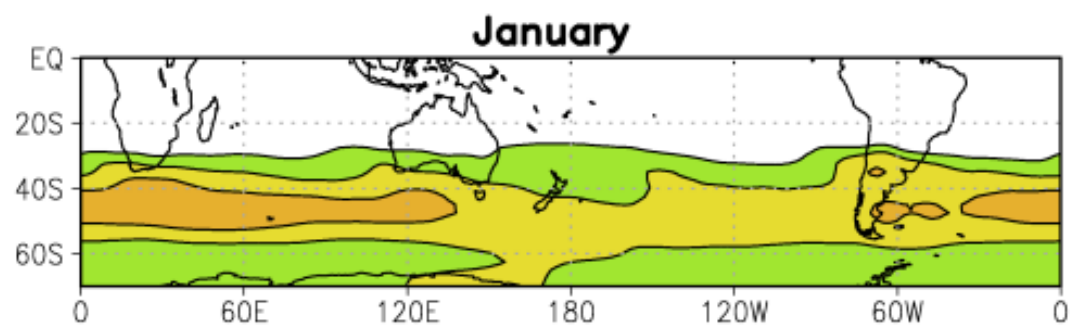

April
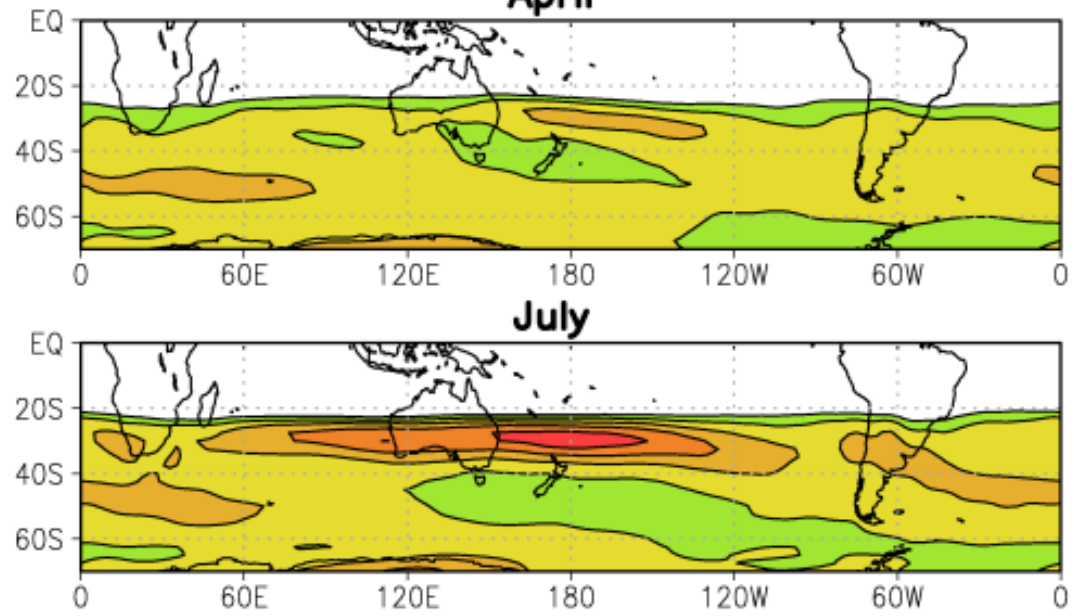

October
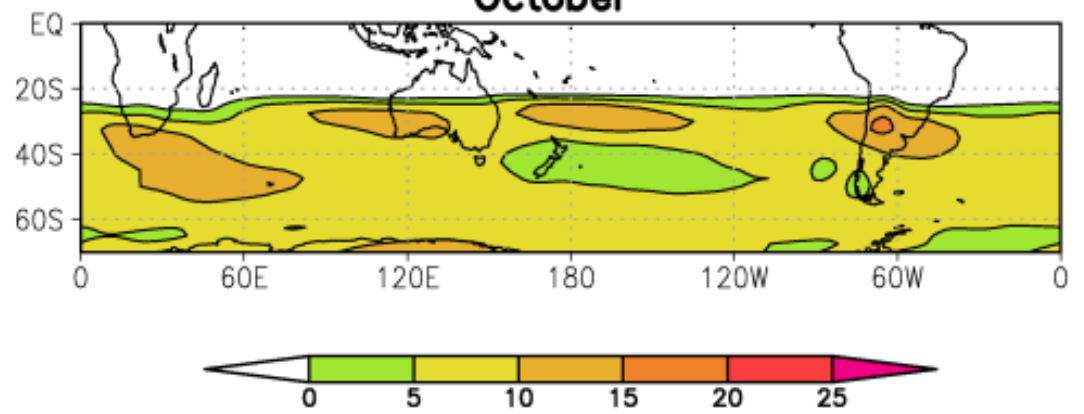
Figure 2: NCEP Phillips criterion climatology linear trend $\left(\mathrm{m} \mathrm{s}^{-1} /\right.$ year $)$ during 1950-1999, for January, April, July and October. Significant trends at the $95 \%$ level are shaded.

\section{Phillips Criterion Trend}

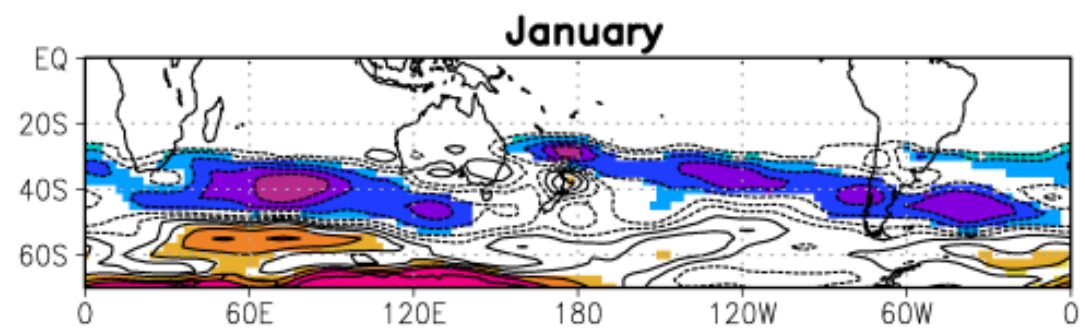

April

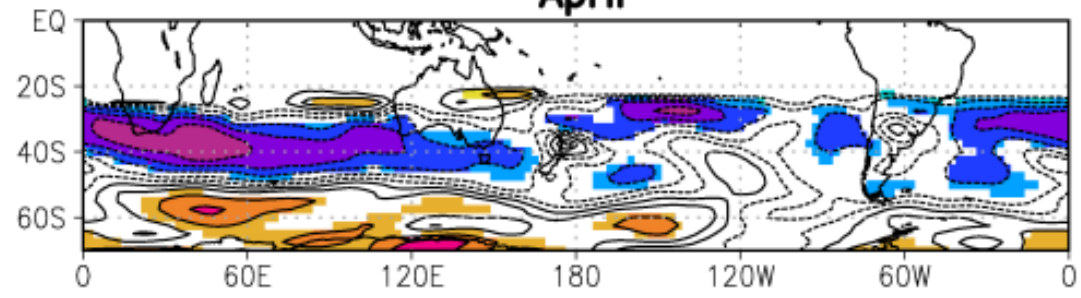

July

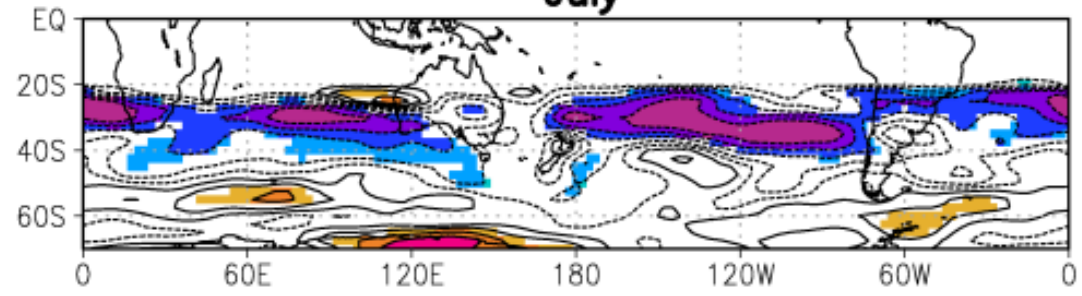

October

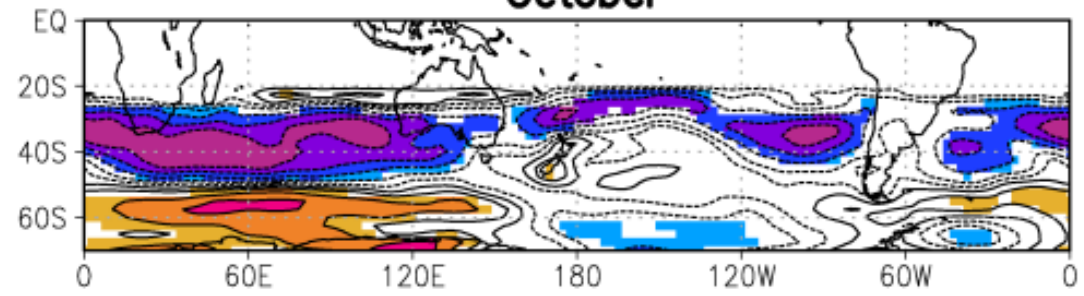


as $0.09 \mathrm{~ms}^{-1}$ year $^{-1}$. This implies, for each month, that there should be an increased chance of storm development in these higher latitude regions. Thus, over the fifty year period, it is expected that the growth rates of the climatological storms, upstream of Australia, should be reduced, and some storms are more likely to develop further south. This is examined in more detail in the next section.

\section{Changes in storm track modes}

Here, changes in the leading storm track modes during the 20th century are examined, focussing on the differences in the periods 1949-1968 and 19972006, during the Australian Millenium Drought. The studies are based on the primitive equation instability model of Frederiksen and Frederiksen [3, 8] which is formulated in terms of streamfunction, velocity potential and temperature. The model includes a generalised Kuo-type heating parameterisation with closures for convection and evaporation wind feedback. As detailed by Frederiksen and Frederiksen [8], the equations are linearised about the observed basic states and the perturbation equations are formulated as an eigenvalue-eigenvector problem and solved for the growing modes with complex frequency $\omega=\omega_{r}+i \omega_{i}$, where $\omega_{r}$ is the frequency and $\omega_{i}$ is the growth rate, and related periods $T=2 \pi / \omega_{\mathrm{r}}$. A resolution of rhomboidal wavenumber 15 truncation is used (i.e., a grid of $750 \mathrm{~km}$ in longitude and $500 \mathrm{~km}$ in latitude at $30^{\circ} \mathrm{S}$ ) and the heating and dissipation parameters are as described by Frederiksen and Frederiksen [8].

In this study we are only interested in the leading, or fastest growing, instability modes that are related to midlatitude storm formation. There are many other important weather modes, including, for example, modes related to atmospheric blocking or intraseasonal variability, which are not our focus here. The storm track modes need not always be the fastest growing weather phenomena. For January the leading southern hemisphere storm track modes are both the fastest growing modes for the respective time intervals, and 
their periods and growth rates are (2.0 days, 0.460 day $\left.^{-1}\right)$ for $1949-68$ and (1.8 days, 0.0440 day $^{-1}$ ) for 1997-06. Thus there is little difference in the growth and propagation characteristics of these two modes. However, Figure 3a shows that for 1949-68 the storm track $700 \mathrm{hPa}$ streamfunction has largest amplitudes at the longitudes of Australia and New Zealand and affects south-eastern Australia while for the drought period (Figure 4a) the mode misses Australia altogether. These different properties are also seen in the other ten leading storm track modes between the early and latter periods (not shown).

The leading southern hemisphere April cyclogenesis modes are the eighth and ninth fastest growing instability modes for 1949-68 with periods and growth rates of ( 2.6 day, 0.314 day $\left.^{-1}\right)$ and (4.0 day, 0.330 day $^{-1}$ ), respectively, while for the latter period 1997-06 it is mode two with (1.8 day, 0.395 day $^{-1}$ ) characteristics. The $700 \mathrm{hPa}$ disturbance streamfunction for mode eight (not shown) is very similar to that for January in Figure 3a while mode nine is shown in Figure 3b and mode two for 1997-2006 is shown in Figure 4b. Again the growth characteristics are little different for these modes but their structures show important differences in how they impact Australian weather. Mode nine for 1949-68 has a wave train impacting on southern Australia as well as another further south, while mode eight only has minor impact on Tasmania and south-eastern Australia, and mode two for 1997-2006 tracks south of Australia altogether.

In July, the leading southern hemisphere storm track modes for 1949-68 and 1997-2006 are modes one and twelve, respectively, with the same periods of 1.3 days but growth rates of 0.423 day $^{-1}$ and 0.266 day $^{-1}$. Thus there is a $37 \%$ reduction in the growth rate during the Millennium Drought while the disturbances have very similar structures, as shown in Figures $3 \mathrm{c}$ and $4 \mathrm{c}$ for the $700 \mathrm{hPa}$ streamfunctions. This growth rate reduction during the drought reflects the reduction in the trend of baroclinicity of the subtropical jet shown in Figures 1 and 2.

In many respects the qualitative changes in leading southern hemisphere 
Figure 3: Instability modes 1949-68: January, April, July, October.

(a) January 1949-1968

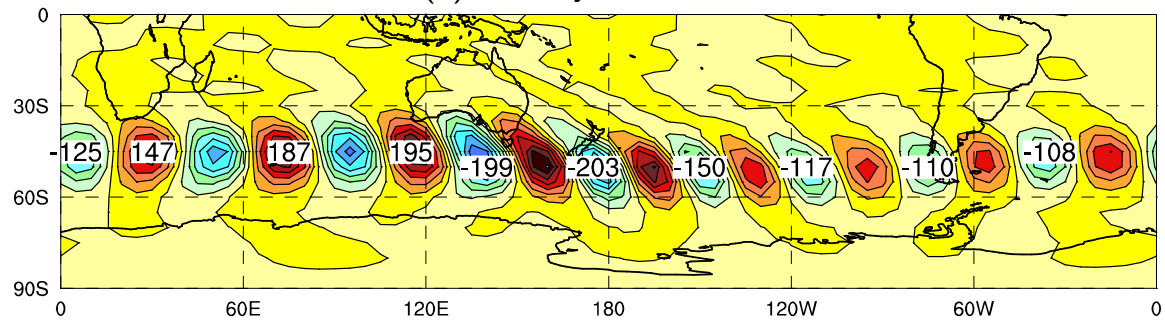

(b) April 1949-1968

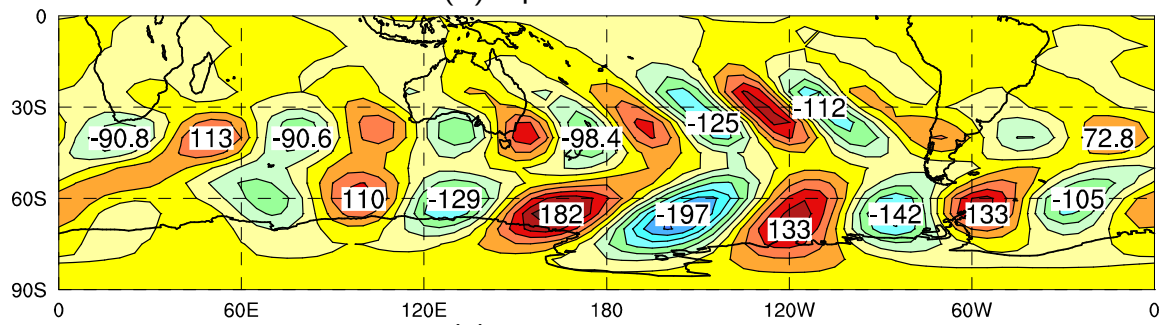

(c) July 1949-1968

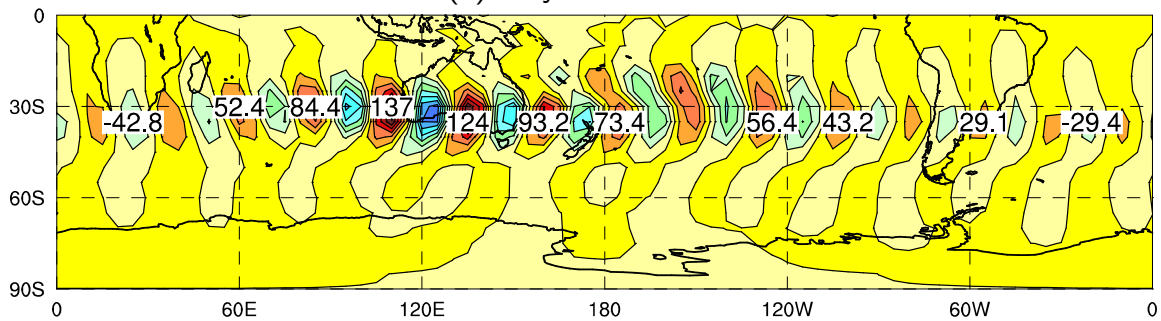

(d) October 1949-1968

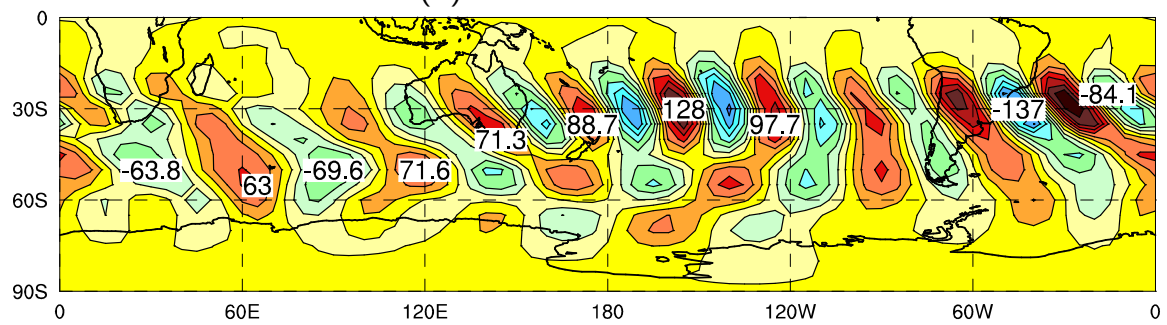


Figure 4: Instability modes 1997-2006: January, April, July, October.

(a) January 1997-2006

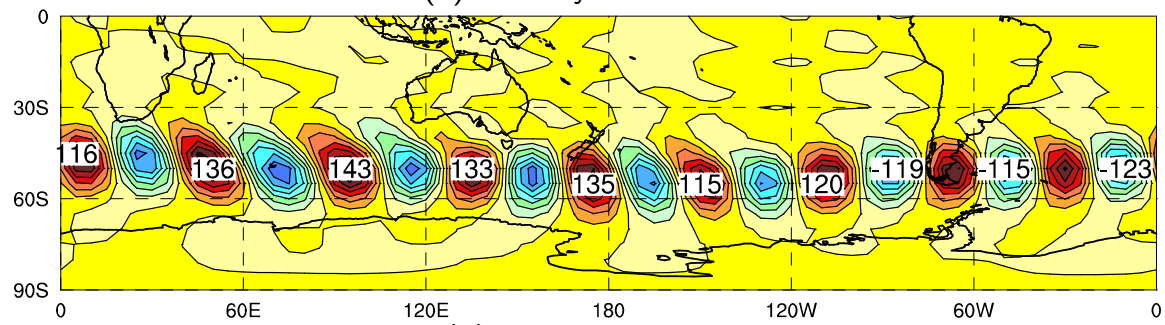

(b) April 1997-2006

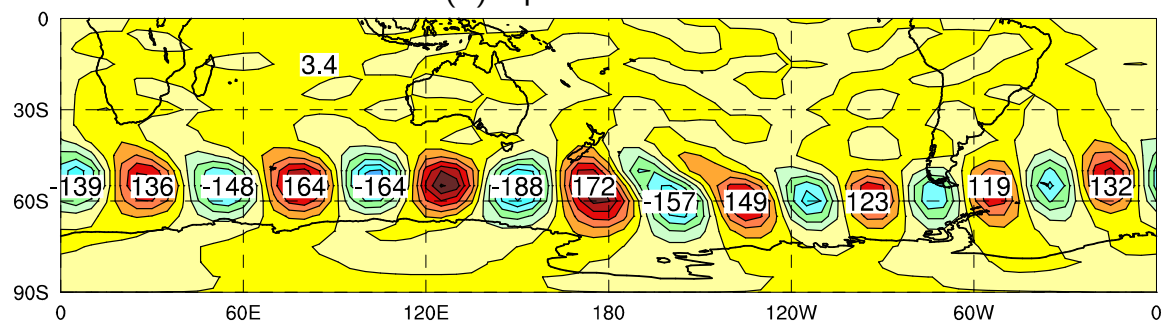

(c) July 1997-2006

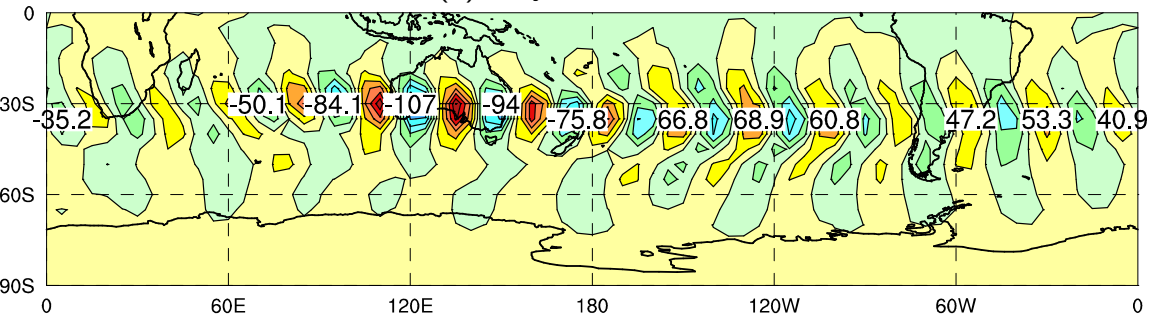

(d) October 1997-2006

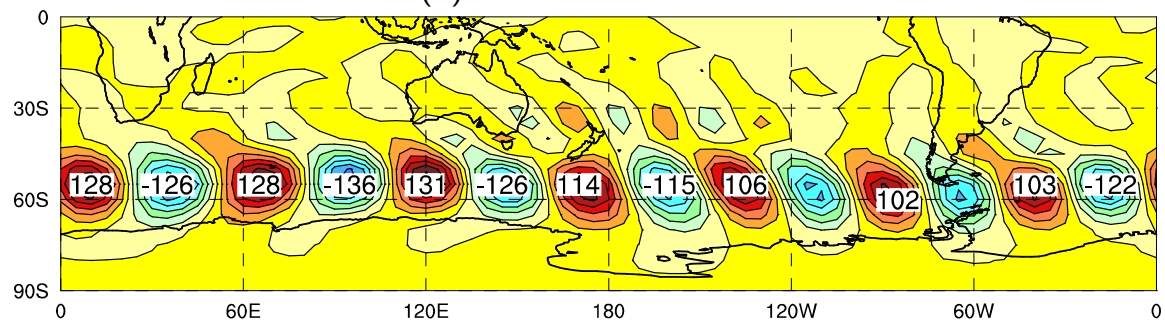


storm track modes between 1949-68 and 1997-2006 in October are similar to those in April. During the central month of the austral springs of 1949-68 the leading southern hemisphere storm track mode is mode nine (Figure 3d) with a period of 2.6 days and growth rate of 0.291 day $^{-1}$, but for 1997-2006 it is mode seven (Figure $4 \mathrm{~d}$ ), with a period of 2.2 days and a growth rate of 0.270 day $^{-1}$. The $700 \mathrm{hPa}$ mode nine streamfunction for 1949-68 again has a large impact on southern Australia while mode seven for 1997-2006 tracks to the south of Australia.

In summary, the changes in the properties of leading southern hemisphere storm track modes between the 1949-68 and 1997-2006 periods are broadly consistent with the trends in baroclinicity (Figures 1 and 2) during the second half of the twentieth century.

\section{CMIP5 models and future projections}

There is a lot of evidence to suggest that the large scale changes in the Southern Hemisphere circulation, and the resulting impacts on weather systems and Australian rainfall trends, are due to trends in anthropogenic greenhouse gas forcing $[11,12]$. It is therefore of interest to know whether these changes and trends in the baroclinic instability are likely to continue under future increases in anthropogenic greenhouse gases. In order to determine this, the CMIP5 models were evaluated for their ability to reproduce the pattern of trends in the Phillips criterion during the period 1950-1999 over the entire annual cycle.

Table 1 shows the twelve best models using their average pattern correlation with the observed trend patterns over the region $\left(0^{\circ} \mathrm{E}-120^{\circ} \mathrm{E}, 20^{\circ} \mathrm{S}-60^{\circ} \mathrm{S}\right)$, over all months, as a measure of their average skill score. This region was chosen because this is the principal area associated with the formation of midlatitude storms that affect southern Australia. A score of one is a perfect score matching exactly the observed trend pattern in all seasons. Frederiksen 


\begin{tabular}{lc} 
Table 1: Skilful CMIP5 models. \\
CMIP5 model & average score \\
\hline MIROC-ESM & 0.48 \\
GFDL-CM3 & 0.44 \\
CSIRO-MK3-6-0 & 0.40 \\
ACCESS1-3 & 0.40 \\
GISS-E2-R & 0.36 \\
MIROC5 & 0.35 \\
IPSL-CM5A-LR & 0.34 \\
FGOALS-S2 & 0.34 \\
HADGEM2-CC & 0.32 \\
CNRM-CM5 & 0.29 \\
CANESM2 & 0.27 \\
MPI-ESM-LR & 0.25
\end{tabular}

et al. [10] documented the models and their origins.

Taking the twelve member ensemble average of climate variables used in equation (1), linear trends were calculated for the Phillips criterion from the RCP8.5 greenhouse gas forcing scenario over the period 2050-2099. The results are shown in Figure 5 (left column) for January, April, July and October. Trends significant at the $95 \%$ level are shaded. While the patterns of positive and negative trends are qualitatively similar to the reanalyzed observations of Figure 2, the calculated trends are about a half of those observed during the twentieth century. Individual models can have trends of similar magnitude to the observed, but the centres of maximum magnitude can vary considerable amongst the models, thus reducing the ensemble average values. These results suggest a continuing reduction in the growth rate of storms growing on the subtropical jet and a preference for modes to grow at higher latitudes.

The impact on Australian rainfall trends is seen in Figure 5 (right column) which shows the corresponding trends in rainfall over this period. Again, significant trends at the $95 \%$ level are shaded. The biggest impacts of the 
Figure 5: CMIP5 models average linear trends $\left(\mathrm{ms}^{-1} /\right.$ year $)$ in Phillips Criterion (left column) and Australian rainfall (mm/day/year)(right column), for January, April, July and October (2050-2099). The 95\% significant trends are shaded.

Phillips Criterion Trend
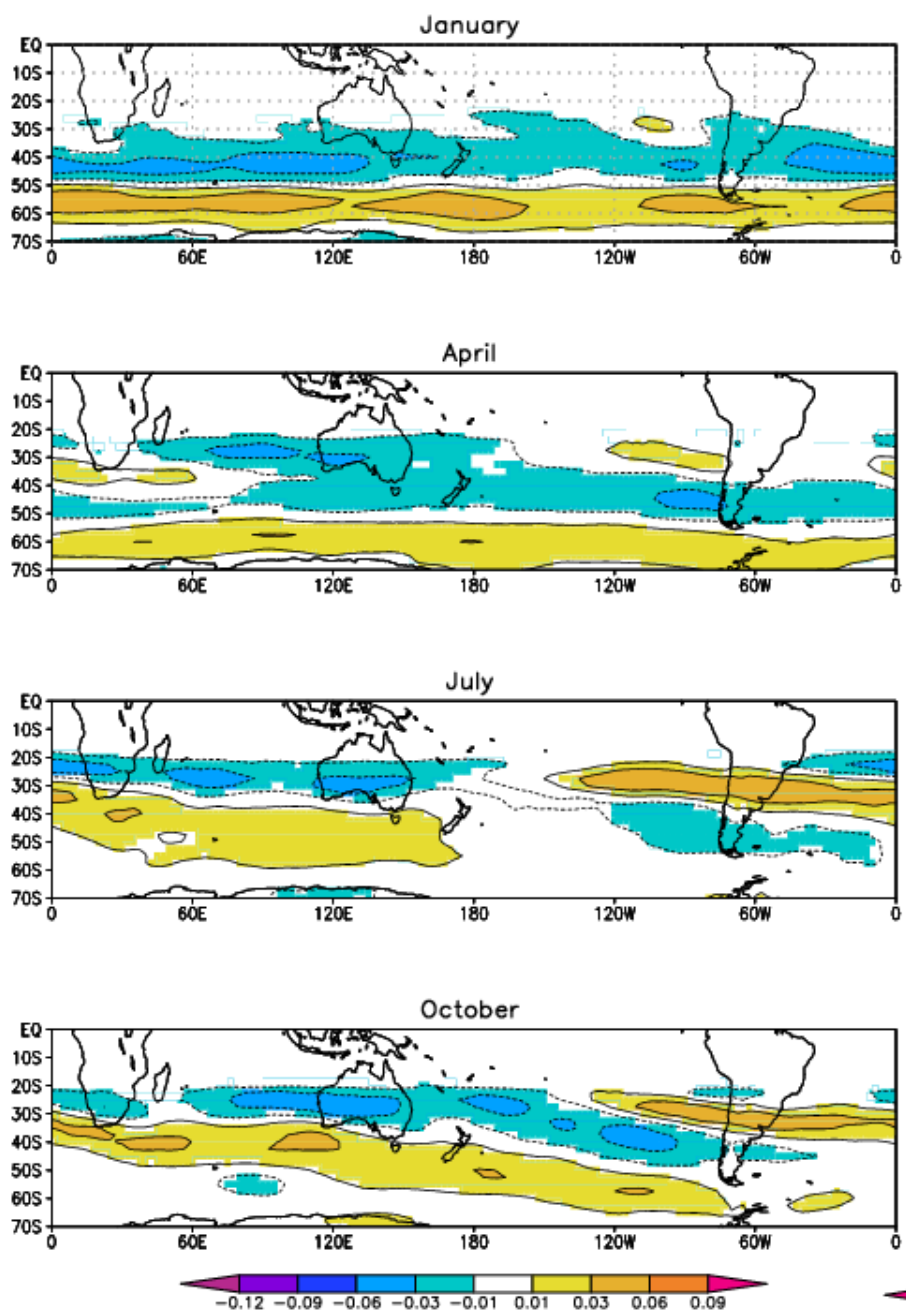

Rainfall Trend January
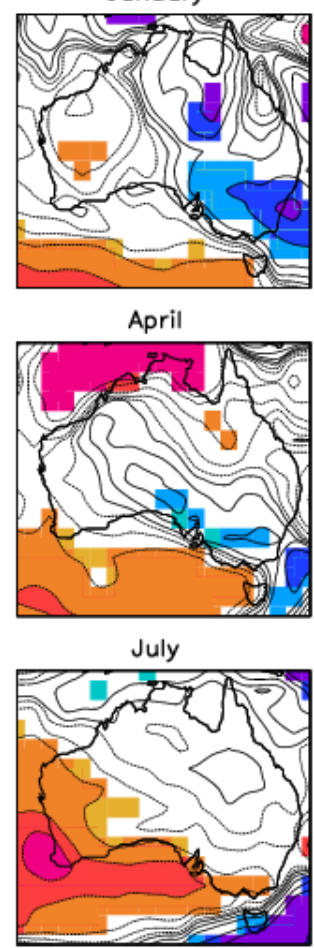

October

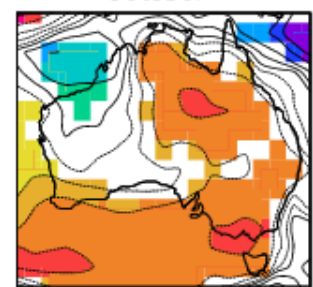

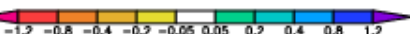


changing nature of the midlatitude storms are seen over southern Australia, especially in winter and spring with significant negative trends over the southwest and southeast. In particular, the observed reduction in rainfall over the southwest Western Australia and southeast Australia looks set to continue under this scenario of increasing anthropogenic greenhouse concentrations. Hemispherically (not shown), the results show that there will generally be large reductions in rainfall in a zonal band between $20^{\circ} \mathrm{S}-40^{\circ} \mathrm{S}$; increases in rainfall are projected south of $40^{\circ} \mathrm{S}$.

\section{Conclusion}

Changes in the annual cycle of southern hemisphere baroclinic instability were examined for the period 1950-1999. There are significant negative trends in a mid-latitude zonal band in all months; a similar band of significant positive trends occurs further poleward. This decrease/increase in baroclinic instability tends to decrease/increase storm formation at these latitudes over this period. This was confirmed by conducting an instability analysis comparing growing storm track modes during the periods 1949-1968, and 1997-2006. The results presented here show that there is a reduction of the intensity of the subtropical storm track and an increase in the polar storm track, particularly during autumn to spring. Future projections of trends in baroclinicity under the RCP8.5 scenario show a similar pattern of negative and positive trends during the period 2050-2099. The impact of these trends is a decreased and negative trends in southern Australian rainfall. Hemispherically, there are generally negative rainfall trends between $20^{\circ} \mathrm{S}-40^{\circ} \mathrm{S}$; poleward of $40^{\circ} \mathrm{S}$ there are generally increases in rainfall.

Acknowledgements This research was partly funded by the Australian Government Department of the Environment through the Australian Climate Change Science Program. 


\section{References}

[1] J. S. Risbey, M. J. Pook, P. C. McIntosh, M. C. Wheeler and H. H. Hendon On the remote drivers of rainfall variability in Australia. Mon. Wea. Rev. 137:3233-3253, 2009. doi:10.1175/2009MWR2861.1 C280

[2] C. S. Frederiksen., X. Zheng and S. Grainger. Teleconnections and predictive characteristics of Australian seasonal rainfall. Clim. Dyn. 43:1381-1408, 2014. doi:10.1007/s00382-013-1952-0 C280

[3] J. S. Frederiksen and C. S. Frederiksen. Interdecadal changes in southern hemisphere winter storm track modes. Tellus, 59:599-617, 2007. doi:10.1111/j.1600-0870.2007.00264.x C280, C282, C285

[4] J. S. Frederiksen and C. S. Frederiksen. Twentieth century winter changes in southern hemisphere synoptic weather modes. Adv. Meteorol. 2011:353829, 2011. doi:10.1155/2011/353829 C280

[5] N. A. Phillips. Energy transformations and meridional circulations associated with simple baroclinic waves in a two-level, quasi-geostrophic model. Tellus, 6:273-286, 1954. doi:10.1111/j.2153-3490.1954.tb01123.x C280, C281

[6] D. P. van Vuuren, J. Edmonds, M. Kainuma, K. Riahi, A. Thomson, K. Hibbard, G. C. Hurtt, T. Kram, V. Krey, J.-F. Lamarque, T. Masui, M. Meinshausen, N. Nakicenovic, S. J. Smith and S. K. Rose. The representative concentration pathways: an overview. Clim. Chang. 109:5-31, 2011. doi:10.1007/s10584-011-0148-z C281

[7] K. E. Taylor, R. J Stouffer and G. A. Meehl. An overview of CMIP5 and the experiment design. Bull. Am. Meteorol. Soc. 93:485-498, 2012. doi:10.1175/BAMS-D-11-00094.1 C281

[8] J. S. Frederiksen and C. S. Frederiksen. Role of dynamical modes in changing southern hemisphere climate. ANZIAM J. 52:C56-C72, 2010. 
http://journal .austms.org.au/ojs/index.php/ANZIAMJ/article/ view/3892 C285

[9] E. Kalnay, M. Kanamitsu, R. Kistler, W. Collins, D. Deaven, L. Gandin, M. Iredell, S. Saha, G. White, J. Woollen, Y. Zhu, A. Leetmaa, R. Reynolds, M. Chelliah, W. Ebisuzaki, W. Higgins, J. Janowiak, K. C. Mo, C. Ropelewski, J. Wang, R. Jenne, and D. Joseph, The NCEP/NCAR 40-Year reanalysis project. Bull Am. Meteorol. Soc. 77:437-471, 1996. doi:10.1175/1520-0477(1996)077<0437:TNYRP>2.0.CO;2 C281

[10] G. Flato et al. Evaluation of climate models. In: T. F. Stocker et al., editors Climate Change 2013: The Physical Science Basis Contribution of Working Group I to the Fifth Assessment Report of the Intergovernmental Panel on Climate Change, Chap. 9, pp. 741-866. Cambridge University Press, Cambridge, UK, 2013 http://www.ipcc.ch/report/ar5/wg1/ C281, C290

[11] C. S. Frederiksen, J. S. Frederiksen, J. M. Sisson and S. L. Osbrough. Changes and Projections in Australian Winter Rainfall and Circulation: Anthropogenic Forcing and Internal Variability. Int. J. Climate Change: Impact. Resp. 2:143-162, 2011. http://ijc.cgpublisher.com/product/pub.185/prod.104 C289

[12] C. S. Frederiksen and S. Grainger. The role of external forcing in prolonged trends in Australian rainfall Clim. Dyn. 45(9):2455-2468, 2015. doi:10.1007/s00382-015-2482-8 C289

\section{Author addresses}

1. C. S. Frederiksen, Bureau of Meteorology, Melbourne 3001, Australia. mailto:csfredoptus@optusnet.com.au 
2. J. S. Frederiksen, CSIRO Oceans and Atmosphere, Aspendale 3195, Australia.

3. J. M. Sisson, Bureau of Meteorology, Melbourne 3001, Australia.

4. S. L. Osbrough, CSIRO Oceans and Atmosphere, Aspendale 3195, Australia. 